\title{
Current questions in bone sarcomas
}

Sandra J Strauss ${ }^{1,2}$ and Jeremy S Whelan ${ }^{1}$

1. University College London Hospitals NHS Trust, 250 Euston Road, London

2. University College London Cancer Institute, 72 Huntley Street, London

Correspondence to: Dr Sandra J Strauss, FRCP, PhD; Department of Oncology, UCL Cancer Institute, 72 Huntley Street, London WC1A 6DD, Te: +44 203447 9346; Fax: +44 203447 9055; email: s.strauss@ucl.ac.uk

Disclosure of funding: Funding was provided to both authors by the National Institute for Health Research, UCLH Biomedical Research Centre

Key words: osteosarcoma; Ewing sarcoma, chondrosarcoma 


\section{Abstract}

Purpose: Osteosarcoma and Ewing sarcoma, the most common primary bone tumours in young people, are curable in most patients. However, these tumours remain a significant challenge due to the complexity and intensity of treatment and its long-term morbidity and the significant proportion of patients in whom treatment is unsuccessful. This review addresses questions about current management and emerging therapeutic targets for patients with osteosarcoma, Ewing sarcoma and chondrosarcoma the commonest bone sarcoma but more common in older patients.

Recent findings: The largest collaborative international study in osteosarcoma, EURAMOS-1 determined that treatment of patients with resectable disease should not be altered on basis of pathological response to neo-adjuvant chemotherapy. In view of little improvement in outcome being evident in recent years, novel therapeutic approaches are required. Putative targets and clinical trials of novel agents are discussed including emerging targets such as PARP inhibition and IDH inhibition in Ewing sarcoma and chondrosarcoma respectively. Newer radiotherapy techniques including proton beam and particle ion therapy may be important for local tumour control in selected patients.

Summary: Collaborative studies are essential to answer current questions and investigate novel therapies in these malignancies to improve outcome and quality of life for patients. 


\section{Introduction}

Bone sarcomas are rare primary bone malignancies, accounting for $<0.2 \%$ of malignant tumours. Osteosarcoma and Ewing sarcoma have a peak incidence in adolescence, with a second peak in OS over 60 years OS (1-3). Chondrosarcoma is the most frequently occurring bone sarcoma of adulthood (1). In adolescents, OS develops most commonly in lower extremity long bones, in older patients there is an increased incidence of craniofacial (CF) and axial tumours (1). ES may involve any bone and also arise less commonly in soft tissues with about $50 \%$ of patients developing extremity tumours, and $25 \%$ pelvic primary tumours. Pain is the most common presenting symptom for patients with bone tumours, but delays in diagnosis are common and patients must be referred to specialist centres for diagnosis and management.

\section{Osteosarcoma}

Conventional high grade OS is the most common histologic type, accounting for approximately $75 \%$ of all cases, with subtypes classified according to the dominant matrix-producing cells (Table 1) (4, 5). Other rarer subtypes of high-grade central osteosarcomas include telangiectatic and small cell variants. Intermediate and low grade subtypes also exist that have a much lower rate of metastasis and greater overall survival (Table 1). All patients should be staged for bone and lung metastases.

\section{Current Management}

Chemotherapy became the mainstay of therapy for OS following a landmark study demonstrating an increase in 6-year survival from 11 to $61 \%$ with multi-agent therapy (6). Subsequently, a multitude of clinical trials have augmented therapy via dose intensification and addition of chemotherapeutic agents. However, survival rates have largely plateaued. Five year survival of patients with 
resectable disease is approximately $70 \%$ with a combination of methotrexate, adriamycin and cisplatin (MAP) considered to be the standard of care both in US and Europe $(7,8)$.

Complete surgical resection of the primary site and metastatic disease remains essential for cure. Primary tumour resection should be carried out by experts in surgical reconstruction to preserve function but the priority is to achieve adequate surgical margins as intralesional or marginal margins increase local recurrence rate, which is then associated with reduced overall survival (OS) (9). Limb salvage is feasible in most patients with extremity tumours, more challenging are those with pelvic and spinal tumours where complete resection many be highly morbid or not possible (10).

\section{What is the influence of histological response to chemotherapy on management of OS?}

Pathological response to neo-adjuvant chemotherapy is an important prognostic factor in OS and formed the basis for the global EURAMOS-1 study (9). Patients with a good response (> 90\% necrosis) were randomised to the addition of pegylated interferon to MAP chemotherapy and those with a poor response a more intensive regimen incorporating ifosfamide and etoposide (MAPIE). Neither treatment improved survival, with MAPIE increasing toxicity and incidence of second malignancies $(8,11)$. There is therefore no evidence that chemotherapy should be changed on the basis of histological response in resectable OS treated with MAP. For patients with rarer subtypes of OS, including CF tumours, the significance of pathological response to chemotherapy is unknown.

\section{What is the role of mifamurtide in OS?}

Mifamurtide is an immune-stimulating agent which may reduce incidence of lung metastases in OS via activation of macrophages. A large randomised study investigating the addition of ifosfamide as well as mifamurtide to MAP showed no benefit for addition of ifosfamide but an increase in overall 
survival for patients treated with mifamurtide $(12,13)$. However, a consensus on interpretation of the data from this study has not been reached, leading to absence of regulatory approval in the US and variable use across Europe. In the metastatic setting, a limited study failed to demonstrate a significant improvement in outcome (14). The French sarcoma group are currently investigating its role in patients with high risk osteosarcoma (metastatic or localized disease with poor histologic response to neoadjuvant chemotherapy) French Sarcome13/0S2016. This randomized trial, may provide further data on the benefit of mifamurtide, at least in this patient subset.

\section{What is the role of radiotherapy in OS?}

Although OS is regarded as a radioresistant disease, it can be beneficial for symptom control in the palliative setting and considered when a primary tumour is unresectable, when it should be considered in combination with chemotherapy (15). Experience of proton beam (PBT) and carbon ion radiotherapy (CIRT) is increasing for those with inoperable or challenging primary sites with some encouraging results. In a series of 55 OS with inoperable OS treated with PBT, a 5 year local control rate of $72 \%$ and overall survival of $67 \%$ was observed and CIRT given to patients with inoperable osteosarcoma of the trunk, resulted in 5 -year local control of $62 \%(16,17)$.

\section{What is the influence of age on management of OS?}

Several series have demonstrated poor outcomes for older patients with osteosarcoma likely resulting from both chemotherapy intolerance and tumour-related factors, but few clinical trials have been conducted to inform practice $(9,18)$. The recent EURO-B.O.S.S study evaluated outcome in patients over 40 years who received intensive multi-agent chemotherapy that included attenuated doses of methotrexate and although significantly more chemotherapy-related toxicity 
was observed, outcomes were favourable with a 5 -year probability of survival of $66 \%$ for those with localised disease (19). Randomised studies are required to standardise care for these patients.

How should less common subtypes of OS be treated?

Craniofacial OS accounts for approximately $10 \%$ of OS, becoming more frequent in older patients. Complete resection significantly improves local control and outcome $(20,21)$. The role of chemotherapy is less clear however, favourable outcomes have been demonstrated with the use of standard regimens, and should be considered $(20,22)$. Due to the morbidity of surgery, delivery of all chemotherapy prior to surgery may be valuable with PET imaging reported to aid monitoring to ensure ongoing benefit and plan timing of surgery (23). For patients with suspected low grade OS, upfront wide resection is recommended for confirmation of biopsy results and as there is no demonstrated value for chemotherapy, patients should undergo surveillance. There is little evidence to support the use of chemotherapy in patients with periosteal OS if no high grade component is demonstrated (24).

\section{What is the optimal management for patients with metastatic and recurrent OS?}

Approximately $20 \%$ of patients have metastatic disease at diagnosis (9). For those with only lung metastases, cure is achievable if disease is resectable (25). Patients who develop lung metastases after completion of first line therapy, particularly if there is small volume disease and a longer disease-free internal, should be considered for resection as 5 years survival can be $40 \%$ in those who achieve a second surgical remission (26). Focal ablation techniques have been demonstrated to achieve local control of small peripheral lung metastases, however, randomised studies are required to define their role in the curative management of patients $(27,28)$. Patients with bone metastases have a much poorer outlook and consideration should be given to maintenance of quality of life. 
Chemotherapy, usually including ifosfamide, is commonly used for patients with recurrent disease with symptomatic benefit observed in many patients and median overall survival times of approximately 1 year but at the cost of significant toxicity $(29,30)$. Gemcitabine alone or in combination docetaxel also has activity in OS $(31,32)$. Phase II studies investigating novel agents in patients with relapsed OS have rarely reported positive results. A pooled analysis of seven phase II trials conducted by Children's Oncology Group (COG) and its collaborative groups that included strata for recurrent/refractory OS with measurable disease demonstrated a 4-month EFS of $12 \%$; with radiographic responses observed in only 3 of the trials (33).

\section{What are the emerging targets for OS?}

Several groups have undertaken genomic sequence analysis of OS samples to further understand biology and identify molecular targets for therapy. These investigations have revealed significant genomic complexity and profound heterogeneity that makes identification of specific targets challenging. Nearly all OS have alterations of TP53 or associated pathway genes, and mutations in RB1 and deletions of CDKN2A/B are common $(34,35)$. Alterations of members of the PI3K/mTOR pathways were also identified in $24 \%$ of samples in one cohort (35). The largest sequencing study of OS to date identified mutations in insulin-like growth factor (IGF) signalling genes in $7 \%$ of cases and IGF1 receptor (IGF1R) amplification in 14\% of tumours (36). Previous studies involving IFGR inhibitors in OS did not report significant activity but, if these findings are validated, the presence of a potential biomarker makes reconsideration a possibility. FGFR amplification is observed in $8 \%$ of OS patients, associated with a poor histological response to treatment, also providing a potential target for investigation. An exome sequencing study revealed a potential role for Poly (ADP-ribose) polymerase (PARP) inhibition in OS, with a "BRCAness phenotype" demonstrated in a cohort of patients and pre-clinical evidence of PARP inhibitor activity $(37,38)(39)$. These findings require independent validation but give promise for future clinical trials. 
Despite a mutation rate higher than other paediatric cancers, responses to checkpoint inhibitors have been disappointing. Approximately $25 \%$ of osteosarcoma express PDL1 with expression correlating with metastasis and worse outcome (40). However, only 1 of 22 patients had a response to pembroluzimab with a progression-free survival (PFS) rate of $24 \%$ at 8 weeks (41). Combination checkpoint studies are ongoing and may reveal benefit in selected patients.

Several clinical trials have investigated oral tyrosine kinase inhibitors, particularly those that inhibit vascular endothelial growth factor (VEGF), platelet-derived growth factor (PDGR) and mTOR/PI3K. A phase II study of sorafenib demonstrated a 45\% 6-month PFS in patients with recurrent, metastatic OS as did a combination of sorafenib with everolimus, whilst a recent study of gemcitabine and sirolimus demonstrated a PFS of $44 \%$ at 4 months (42-44). Correlative biomarker studies suggest that the treatment may be worth further study in selected patients. Other studies evaluating regorafenib and lenvatinib are ongoing. Denosumab, a human monoclonal antibody that targets the RANKL, is currently under evaluation for patients with recurrent osteosarcoma as is a study of an antibody to the disialogangliosid, GD2, based on evidence that OS has high GD2 expression (45) (46).

\section{Ewing sarcoma}

Ewing sarcoma is a small round cell sarcoma, the main driver being the reciprocal translocation between the EWSR1 and FLI1 genes (EWSR1-FLI1). However, in approximately $10 \%$ of patients, EWSR1 is fused with other ETS transcription factors, including ERG, ETV1, ETV4, or FEV (47). All patients require staging that includes imaging of lungs, bone and bone marrow with $20 \%$ patients having metastases.

\section{Current Management}


The incorporation of multi-agent chemotherapy with an induction regimen, local therapy (surgery, radiation therapy, or both) and consolidation therapy is based on results from clinical trials conducted by collaborative groups over several decades. Overall survival (OS) for patients with localized disease now approaches $65 \%$ to $75 \%$, however, acute and long-term toxicities of therapy remain substantial. Outcome for patients with metastatic disease, particularly those with extrapulmonary and recurrent ES remains poor $(48,49)$

\section{What is the optimal first line therapy in ES?}

The standard of care for patients with newly diagnosed ES in north America is dose-compressed chemotherapy with alternating cycles of vincristine, doxorubicin, and cyclophosphamide with ifosfamide and etoposide, (VDC-IE) (50). Vincristine, ifosfamide, doxorubicin, and etoposide (VIDE) induction with VAl (Vincristine, actinomycin ifosfamide) or VAC (Vincristine, actinomycin, cyclophosphamide) consolidation adopted from EURO-E.W.I.N.G 99 protocol, is considered the standard of care in Europe (51). The current EuroEwing consortium (EEC) study, EuroEwing2012, is comparing the two regimens and will help define an international standard of care. A second randomization is assessing the efficacy of zoledronic acid for localized and lung-only metastatic disease, a question also being addressed in the German collaborative, Ewing2008 study. On the basis of encouraging efficacy in recurrent disease, COG is assessing the value of addition of cyclophosphamide and topotecan to compressed VDC-IE in patients with localised disease (Table 2).

\section{What is the optimal local management of ES?}

A number of factors influence the use of surgery and/or radiotherapy to treat the primary tumour including primary site, size and response to treatment. Although ES is known to be radiosensitive, radiotherapy as a single modality results in a high incidence of local recurrence (up to $30 \%$ to $35 \%$ ), 
particularly for large tumours and is only advised for inoperable tumours (52). Tumour resection is recommended whenever complete or marginal resection is possible. Adjuvant radiotherapy significantly reduces local recurrence in patients with large volume tumours and those with a poor histologic response (53). Preoperative radiation therapy is increasingly been used in patients who are expected to require radiotherapy as lower doses are required, which are likely to be associated with less long-term morbidity. PBT is increasingly being adopted for patients with inoperable tumours or those with tumours in challenging sites such as the spine with encouraging early local control rates (54).

\section{What is the role of High dose chemotherapy in ES?}

The recent EURO-E.W.I.N.G 99 study compared the use of high dose therapy incorporating busulfan and melphalan followed by stem cell rescue with standard consolidation chemotherapy in two cohorts of patients treated with induction chemotherapy and surgical resection. In the first, R2Loc, which included patients with high risk localised disease, (large tumour volume $>200 \mathrm{mls}$ and /or a poor response to induction chemotherapy), the study demonstrated an improvement in 3-year event-free survival (67\% vs. $53 \%$ ) and 3 -year overall survival ( $78 \%$ vs. $70 \%$ ) and so should be considered for this group of patients (55). No benefit was found for patients with pulmonary metastases at diagnosis (R2Pulm) and should not be recommenced in this setting (56). There are no results of randomised studies to support the use of HDT in patients with extra-pulmonary metastatic disease.

What is the optimal therapy for patients with metastatic and relapsed ES?

Patients with metastases at diagnosis have a less favourable outcome, particularly those with extrapulmonary metastatic disease. Patients are treated with standard regimens, however 
considerations to quality of life as well as improving outcome are required in this setting. The COG is investigating the value of addition of the IGF1R monoclonal antibody, ganitumab, to interval compressed VDC/IE in metastatic ES.

In recurrent/ refractory ES, several combination therapies have demonstrated activity, however evidence comes from retrospective analyses and small phase II studies and responses are generally short-lived. The rEECur study, the first EURO-Ewing Consortium (EEC) study for recurrent ES is comparing those most commonly used to identify the optimum therapy based on the efficacy and toxicity (Table 2). The study has a flexible, multi-arm multi-stage phase II/III trial design that allows further arms to be added to the protocol to allow randomised investigation of promising novel therapies.

\section{What are the emerging targets and therapies in ES?}

Studies describing the genomic landscape of Ewing sarcoma, have demonstrated that ES has a low mutational rate. The most common recurrent mutation is found in STAG2, found in $15 \%$ of patients. Other commonly reported genetic alterations include deletion of CDKN2A and mutations in TP53, however, to date these findings have not led to changes in therapy (57). On the basis of preclinical studies demonstrating sensitivity of ES cell lines to PARP inhibition, and potent synergy of PARP inhibitors with temozolomide and irinotecan in ES preclinical models, several international studies are investigating safety and efficacy of these combinations(58-60) (Table 3). Tyrosine kinase inhibitors also undergoing evaluation in ES with a recent study of regorafinib meeting its primary end point, with $60 \%$ patients achieving stable disease at 8 weeks (61). Other novel agents such as TK216 which directly targets the EWS-FLI1 interaction with a partner protein RNA helicase A has recently entered a phase I clinical trial (62).Inhibition of the transrepressive functions of EWSR1-FLI1 through the use of lysine-specific histone demethylase inhibitors also appears promising (63). Response to 
single agent checkpoint inhibition however, has been disappointing and further work is required to determine the place of immunotherapy in ES (41).

\section{Chondrosarcoma}

Surgical resection of disease is the mainstay of therapy for patients with the most common subtype, conventional chondrosarcoma (Table 4). Cure rates are high if disease is low grade, where extensive intralesional curettage may be considered to reduce morbidity. Intermediate and high-grade tumours however, require wide, en-bloc resection. Dedifferentiated chondrosarcoma, which accounts for approximately $10 \%$ of chondrosarcoma, is commonly associated with development of bone and lung metastases and very poor survival. Adjuvant chemotherapy as given for OS may be considered in younger patients with localized dedifferentiated chondrosarcoma. Patients with advanced disease and good performance may benefit from the palliative use of cisplatin and doxorubicin. In mesenchymal chondrosarcoma, adjuvant chemotherapy is associated with reduced risk of recurrence and death (64).

\section{What is the role of radiotherapy in chondrosarcoma?}

Chondrosarcomas (CS) are considered radioresistant tumours, thus high doses are required to be effective. PBT and CIRT, which are able to deliver doses over $70 \mathrm{~Gy}$, are beginning to demonstrate benefit in chondrosarcoma with high local control rates for skull base and spinal CS up to 7 years after therapy with acceptable late toxicity $(65,66)$. 
Chondrosarcomas are resistant to chemotherapy, thus new therapeutic approaches are needed for unresectable or metastatic disease. IDH1 and IDH2 mutations have been identified in more than $50 \%$ of patients with conventional chondrosarcoma and offers a promising new target with several clinical trials evaluating the clinical activity of novel IDH inhibitors (67). A phase II study, investigating the efficacy and safety of pazopanib, a potent multitargeted RTK inhibitor in patients with unresectable or metastatic chondrosarcoma has recently completed accrual (NCT01330966).

\section{Conclusion}

Although significant advances have been made in management of bone tumours, therapy is complex and patients require management at specialist centres. Continued collaboration is essential to answer current questions and investigate novel therapies in these malignancies to improve outcome and quality of life for patients. Ideally studies should be conducted with standardised endpoints and biomarkers that better predict response and outcome are of paramount importance. Questions also remain how best to incorporating new agents into front-line therapy. For novel radiotherapy techniques, further follow is required to determine impact on long term morbidity and second malignancy.

\section{Key points}

1. Primary bone sarcomas require complex management that should be undertaken in specialist centres only

2. There is no evidence that altering chemotherapy on the basis of pathological response to chemotherapy improves outcome in patients with resectable osteosarcoma

3. High dose chemotherapy with stem cell support improves outcome in selected Ewing sarcoma patients with high risk localised disease 
4. Collaborative studies and randomised trials are required to validate novel therapies and radiotherapy techniques

Acknowledgements: Funding was provided to both authors by the National Institute for Health Research, UCLH Biomedical Research Centre

Conflicts of interest: none 


\section{References}

1. Whelan J, McTiernan A, Cooper N, Wong YK, Francis M, Vernon S, et al. Incidence and survival of malignant bone sarcomas in England 1979-2007. International journal of cancer Journal international du cancer. 2012;131(4):E508-17.

2. Mirabello L, Troisi RJ, Savage SA. International osteosarcoma incidence patterns in children and adolescents, middle ages and elderly persons. International journal of cancer Journal international du cancer. 2009;125(1):229-34.

3. Mirabello L, Troisi RJ, Savage SA. Osteosarcoma incidence and survival rates from 1973 to 2004: data from the Surveillance, Epidemiology, and End Results Program. Cancer. 2009;115(7):1531-43.

4. Fletcher CDM, J.A.; B, Hogendoorn P, (eds): ea. WHO classification of tumours of soft tissue and bone. 4th ed. Lyon, France: IARC Press; 2013.

5. Whelan JS, Davis LE. Osteosarcoma, Chondrosarcoma, and Chordoma. Journal of clinical oncology : official journal of the American Society of Clinical Oncology. 2018;36(2):188-93.

6. Link MP, Goorin AM, Miser AW, Green AA, Pratt CB, Belasco JB, et al. The effect of adjuvant chemotherapy on relapse-free survival in patients with osteosarcoma of the extremity. The New England journal of medicine. 1986;314(25):1600-6.

7. Ferrari S, Ruggieri P, Cefalo G, Tamburini A, Capanna R, Fagioli F, et al. Neoadjuvant chemotherapy with methotrexate, cisplatin, and doxorubicin with or without ifosfamide in nonmetastatic osteosarcoma of the extremity: an Italian sarcoma group trial ISG/OS-1. Journal of clinical oncology. 2012;30(17):2112-8.

8. ${ }^{* *}$ Bielack SS, Smeland S, Whelan JS, Marina N, Jovic G, Hook JM, et al. Methotrexate, Doxorubicin, and Cisplatin (MAP) Plus Maintenance Pegylated Interferon Alfa-2b Versus MAP Alone in Patients With Resectable High-Grade Osteosarcoma and Good Histologic Response to Preoperative MAP: First Results of the EURAMOS-1 Good Response Randomized Controlled Trial. Journal of clinical oncology. 2015;33(20):2279-87. The first results of international Euramos study demonstrates no improvement in outcome for good risk OS patients with addition of interferon

9. Bielack SS, Kempf-Bielack B, Delling G, Exner GU, Flege S, Helmke K, et al. Prognostic factors in high-grade osteosarcoma of the extremities or trunk: an analysis of 1,702 patients treated on neoadjuvant cooperative osteosarcoma study group protocols. Journal of clinical oncology : official journal of the American Society of Clinical Oncology. 2002;20(3):776-90.

10. Group EESNW. Bone sarcomas: ESMO Clinical Practice Guidelines for diagnosis, treatment and follow-up. Annals of oncology : official journal of the European Society for Medical Oncology / ESMO. 2014;25 (Suppl 3): :iii113-23.

11. ${ }^{* *}$ Marina NM, Smeland S, Bielack SS, Bernstein M, Jovic G, Krailo MD, et al. Comparison of MAPIE versus MAP in patients with a poor response to preoperative chemotherapy for newly diagnosed high-grade osteosarcoma (EURAMOS-1): an open-label, international, randomised controlled trial. The Lancet Oncology. 2016. International study demonstrates no role for intensification of therapy in patients with a poor response to neo-adjuvant chemtoherapy. 
12. Meyers PA, Schwartz CL, Krailo M, Kleinerman ES, Betcher D, Bernstein ML, et al. Osteosarcoma: a randomized, prospective trial of the addition of ifosfamide and/or muramyl tripeptide to cisplatin, doxorubicin, and high-dose methotrexate. Journal of clinical oncology : official journal of the American Society of Clinical Oncology. 2005;23(9):2004-11.

13. Meyers PA, Schwartz CL, Krailo MD, Healey JH, Bernstein ML, Betcher $D$, et al. Osteosarcoma: the addition of muramyl tripeptide to chemotherapy improves overall survival--a report from the Children's Oncology Group. Journal of clinical oncology : official journal of the American Society of Clinical Oncology. 2008;26(4):633-8.

14. Chou AJ, Kleinerman ES, Krailo MD, Chen Z, Betcher DL, Healey JH, et al. Addition of muramyl tripeptide to chemotherapy for patients with newly diagnosed metastatic osteosarcoma: a report from the Children's Oncology Group. Cancer. 2009;115(22):5339-48.

15. Schwarz R, Bruland O, Cassoni A, Schomberg P, Bielack S. The role of radiotherapy in oseosarcoma. Cancer treatment and research. 2009;152:147-64.

16. Ciernik IF, Niemierko A, Harmon DC, Kobayashi W, Chen YL, Yock TI, et al. Proton-based radiotherapy for unresectable or incompletely resected osteosarcoma. Cancer. 2011;117(19):452230.

17. Matsunobu A, Imai R, Kamada T, Imaizumi T, Tsuji $H$, Tsujii $H$, et al. Impact of carbon ion radiotherapy for unresectable osteosarcoma of the trunk. Cancer. 2012;118(18):4555-63.

18. Grimer RJ, Cannon SR, Taminiau AM, Bielack S, Kempf-Bielack B, Windhager R, et al. Osteosarcoma over the age of forty. European journal of cancer. 2003;39(2):157-63.

19. *Ferrari S, Bielack SS, Smeland S, Longhi A, Egerer G, Sundby Hall K, et al. EURO-B.O.S.S.: A European study on chemotherapy in bone-sarcoma patients aged over 40: Outcome in primary highgrade osteosarcoma. Tumori. 2017:0. European study describing favourable outcome in older patients who receive intensive chemotherapy.

20. Jasnau S, Meyer U, Potratz J, Jundt G, Kevric M, Joos UK, et al. Craniofacial osteosarcoma Experience of the cooperative German-Austrian-Swiss osteosarcoma study group. Oral oncology. 2008;44(3):286-94.

21. Konig M, Osnes TA, Lobmaier I, Bjerkehagen B, Bruland OS, Sundby Hall K, et al. Multimodal treatment of craniofacial osteosarcoma with high-grade histology. A single-center experience over 35 years. Neurosurgical review. 2017;40(3):449-60.

22. Smeele LE, Kostense PJ, van der Waal I, Snow GB. Effect of chemotherapy on survival of craniofacial osteosarcoma: a systematic review of 201 patients. Journal of clinical oncology : official journal of the American Society of Clinical Oncology. 1997;15(1):363-7.

23. Frezza AM, Beale T, Bomanji J, Jay A, Kalavrezos N, Dileo P, et al. Is [F-18]-fluorodeoxy-Dglucose positron emission tomography of value in the management of patients with craniofacial bone sarcomas undergoing neo-adjuvant treatment? BMC cancer. 2014;14:23.

24. Cesari M, Alberghini M, Vanel D, Palmerini E, Staals EL, Longhi A, et al. Periosteal osteosarcoma: a single-institution experience. Cancer. 2011;117(8):1731-5.

25. Kager L, Zoubek A, Potschger U, Kastner U, Flege S, Kempf-Bielack B, et al. Primary metastatic osteosarcoma: presentation and outcome of patients treated on neoadjuvant 
Cooperative Osteosarcoma Study Group protocols. Journal of clinical oncology : official journal of the American Society of Clinical Oncology. 2003;21(10):2011-8.

26. Diemel KD, Klippe HJ, Branseheid D. Pulmonary metastasetomy for osteosarcoma: is it justified? Recent results in cancer research Fortschritte der Krebsforschung Progres dans les recherches sur le cancer. 2009;179:183-208.

27. Koelblinger $C$, Strauss S, Gillams A. Outcome after radiofrequency ablation of sarcoma lung metastases. Cardiovascular and interventional radiology. 2014;37(1):147-53.

28. Yevich S, Gaspar N, Tselikas L, Brugieres L, Pacquement H, Schleiermacher G, et al. Percutaneous Computed Tomography-Guided Thermal Ablation of Pulmonary Osteosarcoma Metastases in Children. Annals of surgical oncology. 2016;23(4):1380-6.

29. Gentet JC, Brunat-Mentigny M, Demaille MC, Pein F, Avet-Loiseau H, Berger C, et al. Ifosfamide and etoposide in childhood osteosarcoma. A phase II study of the French Society of Paediatric Oncology. European journal of cancer. 1997;33(2):232-7.

30. Patel SR, Vadhan-Raj S, Papadopolous N, Plager C, Burgess MA, Hays C, et al. High-dose ifosfamide in bone and soft tissue sarcomas: results of phase II and pilot studies--dose-response and schedule dependence. Journal of clinical oncology : official journal of the American Society of Clinical Oncology. 1997;15(6):2378-84.

31. Fox E, Patel S, Wathen JK, Schuetze S, Chawla S, Harmon D, et al. Phase II study of sequential gemcitabine followed by docetaxel for recurrent Ewing sarcoma, osteosarcoma, or unresectable or locally recurrent chondrosarcoma: results of Sarcoma Alliance for Research Through Collaboration Study 003. The oncologist. 2012;17(3):321.

32. Palmerini E, Jones RL, Marchesi E, Paioli A, Cesari M, Longhi A, et al. Gemcitabine and docetaxel in relapsed and unresectable high-grade osteosarcoma and spindle cell sarcoma of bone. BMC cancer. 2016;16:280.

33. *Lagmay JP, Krailo MD, Dang H, Kim A, Hawkins DS, Beaty O, 3rd, et al. Outcome of Patients With Recurrent Osteosarcoma Enrolled in Seven Phase II Trials Through Children's Cancer Group, Pediatric Oncology Group, and Children's Oncology Group: Learning From the Past to Move Forward. Journal of clinical oncology. 2016;34(25):3031-8. Analysis of phase II studies that recruited osterrosarcoma paitents demonstrating limited benefit and challenges with using RECIST as response assessment

34. Chen X, Bahrami A, Pappo A, Easton J, Dalton J, Hedlund E, et al. Recurrent somatic structural variations contribute to tumorigenesis in pediatric osteosarcoma. Cell reports. 2014;7(1):104-12.

35. Perry JA, Kiezun A, Tonzi P, Van Allen EM, Carter SL, Baca SC, et al. Complementary genomic approaches highlight the $\mathrm{PI} 3 \mathrm{~K} / \mathrm{mTOR}$ pathway as a common vulnerability in osteosarcoma. Proceedings of the National Academy of Sciences of the United States of America. 2014;111(51):E5564-73.

36. ${ }^{* *}$ Behjati S, Tarpey PS, Haase K, Ye H, Young MD, Alexandrov LB, et al. Recurrent mutation of IGF signalling genes and distinct patterns of genomic rearrangement in osteosarcoma. Nature communications. 2017;8:15936. Results of most comprehensive genetic sequencing study of children and adults with osteosarcoma confirming tumour heterogeneity but a potential role for IGF inhibtion in OS 
37. Fernanda Amary M, Ye H, Berisha F, Khatri B, Forbes G, Lehovsky K, et al. Fibroblastic growth factor receptor 1 amplification in osteosarcoma is associated with poor response to neo-adjuvant chemotherapy. Cancer medicine. 2014;3(4):980-7.

38. Kovac M, Blattmann C, Ribi S, Smida J, Mueller NS, Engert F, et al. Exome sequencing of osteosarcoma reveals mutation signatures reminiscent of BRCA deficiency. Nature communications. 2015;6:8940.

39. Engert F, Kovac M, Baumhoer D, Nathrath M, Fulda S. Osteosarcoma cells with genetic signatures of BRCAness are susceptible to the PARP inhibitor talazoparib alone or in combination with chemotherapeutics. Oncotarget. 2017;8(30):48794-806.

40. Sundara YT, Kostine M, Cleven AH, Bovee JV, Schilham MW, Cleton-Jansen AM. Increased PD-L1 and T-cell infiltration in the presence of HLA class I expression in metastatic high-grade osteosarcoma: a rationale for T-cell-based immunotherapy. Cancer immunology, immunotherapy : ClI. 2017;66(1):119-28.

41. **Tawbi HA, Burgess M, Bolejack V, Van Tine BA, Schuetze SM, Hu J, et al. Pembrolizumab in advanced soft-tissue sarcoma and bone sarcoma (SARC028): a multicentre, two-cohort, single-arm, open-label, phase 2 trial. The Lancet Oncology. 2017;18(11):1493-501. Phase II study evaluating the checkpoint inhibitor, pembrolizumab in sarcomas that demonstrated disappointing efficacy in osteosarcoma and Ewing sarcoma

42. Grignani G, Palmerini E, Dileo P, Asaftei SD, D'Ambrosio L, Pignochino Y, et al. A phase II trial of sorafenib in relapsed and unresectable high-grade osteosarcoma after failure of standard multimodal therapy: an Italian Sarcoma Group study. Annals of oncology : official journal of the European Society for Medical Oncology / ESMO. 2012;23(2):508-16.

43. Grignani G, Palmerini E, Ferraresi V, D'Ambrosio L, Bertulli R, Asaftei SD, et al. Sorafenib and everolimus for patients with unresectable high-grade osteosarcoma progressing after standard treatment: a non-randomised phase 2 clinical trial. The Lancet Oncology. 2015;16(1):98-107.

44. *Martin-Broto J, Redondo A, Valverde C, Vaz MA, Mora J, Garcia Del Muro X, et al. Gemcitabine plus sirolimus for relapsed and progressing osteosarcoma patients after standard chemotherapy: a multicenter, single-arm phase II trial of Spanish Group for Research on Sarcoma (GEIS). Annals of oncology : official journal of the European Society for Medical Oncology / ESMO. 2017;28(12):2994-9. Phase II study demonstrating PFS of $44 \%$ at 4 months. Correlative biomarker studies suggest that the treatment may be worth further study in selected patients.

45. Branstetter D, Rohrbach K, Huang LY, Soriano R, Tometsko M, Blake M, et al. RANK and RANK ligand expression in primary human osteosarcoma. Journal of bone oncology. 2015;4(3):59-68.

46. Roth M, Linkowski M, Tarim J, Piperdi S, Sowers R, Geller D, et al. Ganglioside GD2 as a therapeutic target for antibody-mediated therapy in patients with osteosarcoma. Cancer. 2014;120(4):548-54.

47. Ginsberg JP, de Alava E, Ladanyi M, Wexler LH, Kovar H, Paulussen M, et al. EWS-FLI1 and EWS-ERG gene fusions are associated with similar clinical phenotypes in Ewing's sarcoma. Journal of clinical oncology : official journal of the American Society of Clinical Oncology. 1999;17(6):1809-14. 
48. Rodriguez-Galindo C, Navid F, Liu T, Billups CA, Rao BN, Krasin MJ. Prognostic factors for local and distant control in Ewing sarcoma family of tumors. Annals of oncology : official journal of the European Society for Medical Oncology / ESMO. 2008;19(4):814-20.

49. Ladenstein R, Potschger U, Le Deley MC, Whelan J, Paulussen M, Oberlin O, et al. Primary disseminated multifocal Ewing sarcoma: results of the Euro-EWING 99 trial. Journal of clinical oncology : official journal of the American Society of Clinical Oncology. 2010;28(20):3284-91.

50. Womer RB, West DC, Krailo MD, Dickman PS, Pawel BR, Grier HE, et al. Randomized controlled trial of interval-compressed chemotherapy for the treatment of localized Ewing sarcoma: a report from the Children's Oncology Group. Journal of clinical oncology : official journal of the American Society of Clinical Oncology. 2012;30(33):4148-54.

51. Le Deley MC, Paulussen M, Lewis I, Brennan B, Ranft A, Whelan J, et al. Cyclophosphamide compared with ifosfamide in consolidation treatment of standard-risk Ewing sarcoma: results of the randomized noninferiority Euro-EWING99-R1 trial. Journal of clinical oncology : official journal of the American Society of Clinical Oncology. 2014;32(23):2440-8.

52. DuBois SG, Krailo MD, Gebhardt MC, Donaldson SS, Marcus KJ, Dormans J, et al. Comparative evaluation of local control strategies in localized Ewing sarcoma of bone: a report from the Children's Oncology Group. Cancer. 2015;121(3):467-75.

53. Foulon S, Brennan B, Gaspar N, Dirksen U, Jeys L, Cassoni A, et al. Can postoperative radiotherapy be omitted in localised standard-risk Ewing sarcoma? An observational study of the Euro-E.W.I.N.G group. European journal of cancer. 2016;61:128-36.

54. Rombi B, DeLaney TF, MacDonald SM, Huang MS, Ebb DH, Liebsch NJ, et al. Proton radiotherapy for pediatric Ewing's sarcoma: initial clinical outcomes. International journal of radiation oncology, biology, physics. 2012;82(3):1142-8.

55. Whelan J, Le Deley MC, Dirksen U, Judson I, Hawkins D, Van den Berg H. Efficacy of busulfanmelphalan high dose chemotherapy consolidation (BuMel) in localized high-risk Ewing sarcoma (ES): Results of EURO-EWING 99-R2 randomized trial (EE99R2Loc). Journal of clinical oncology : official journal of the American Society of Clinical Oncology. 2016;34, (15_suppl 11000).

56. Dirksen U, Le Deley MC, Brennan B, Judson IR, Bernstein ML, Gorlick RG. Efficacy of busulfanmelphalan high dose chemotherapy consolidation (BuMel) compared to conventional chemotherapy combined with lung irradiation in ewing sarcoma (ES) with primary lung metastases: Results of EURO-EWING 99-R2pulm randomized trial (EE99R2pul). Journal of clinical oncology : official journal of the American Society of Clinical Oncology. 2016;34 (15 suppl.):11001.

57. Tirode F, Surdez D, Ma X, Parker M, Le Deley MC, Bahrami A, et al. Genomic landscape of Ewing sarcoma defines an aggressive subtype with co-association of STAG2 and TP53 mutations. Cancer discovery. 2014;4(11):1342-53.

58. Garnett MJ, Edelman EJ, Heidorn SJ, Greenman CD, Dastur A, Lau KW, et al. Systematic identification of genomic markers of drug sensitivity in cancer cells. Nature. 2012;483(7391):570-5.

59. Brenner JC, Feng FY, Han S, Patel S, Goyal SV, Bou-Maroun LM, et al. PARP-1 inhibition as a targeted strategy to treat Ewing's sarcoma. Cancer research. 2012;72(7):1608-13.

60. Stewart E, Goshorn R, Bradley C, Griffiths LM, Benavente C, Twarog NR, et al. Targeting the DNA repair pathway in Ewing sarcoma. Cell reports. 2014;9(3):829-41. 
61. Attia S, Bolejack V, Ganjoo KN, George S, Agulnik M, Rushing DA, et al. A phase II trial of regorafenib (REGO) in patients (pts) with advanced Ewing sarcoma and related tumors (EWS) of soft tissue and bone: SARC024 trial results. Journal of Clinical Oncology. 2017;35(15_suppl):11005-.

62. Erkizan HV, Kong $\mathrm{Y}$, Merchant $\mathrm{M}$, Schlottmann S, Barber-Rotenberg JS, Yuan L, et al. A small molecule blocking oncogenic protein EWS-FLI1 interaction with RNA helicase A inhibits growth of Ewing's sarcoma. Nature medicine. 2009;15(7):750-6.

63. Theisen ER, Pishas KI, Saund RS, Lessnick SL. Therapeutic opportunities in Ewing sarcoma: EWS-FLI inhibition via LSD1 targeting. Oncotarget. 2016;7(14):17616-30.

64. Frezza AM, Cesari M, Baumhoer D, Biau D, Bielack S, Campanacci DA, et al. Mesenchymal chondrosarcoma: prognostic factors and outcome in 113 patients. A European Musculoskeletal Oncology Society study. European journal of cancer. 2015;51(3):374-81.

65. Weber DC, Badiyan S, Malyapa R, Albertini F, Bolsi A, Lomax AJ, et al. Long-term outcomes and prognostic factors of skull-base chondrosarcoma patients treated with pencil-beam scanning proton therapy at the Paul Scherrer Institute. Neuro-oncology. 2016;18(2):236-43.

66. Demizu $Y$, Mizumoto $M$, Onoe $T$, Nakamura N, Kikuchi $Y$, Shibata $T$, et al. Proton beam therapy for bone sarcomas of the skull base and spine: A retrospective nationwide multicenter study in Japan. Cancer science. 2017;108(5):972-7.

67. Amary MF, Bacsi K, Maggiani F, Damato S, Halai D, Berisha F, et al. IDH1 and IDH2 mutations are frequent events in central chondrosarcoma and central and periosteal chondromas but not in other mesenchymal tumours. The Journal of pathology. 2011;224(3):334-43. 
Table 1 Subtypes of osteosarcoma

\begin{tabular}{|l|l|l|}
\hline WHO Classification & Grade & Incidence (\% of OS) \\
\hline $\begin{array}{l}\text { Conventional } \\
\text { chondroblastic, fibroblastic, osteoblastic }\end{array}$ & High & Common (>75) \\
\hline Telangectatic & High & Rare \\
\hline Small cell & High & Rare (4\%) \\
\hline High grade surface & High & Rare (<1) \\
\hline Periosteal & Intermediate & Rare (1-2) \\
\hline Low Grade central & Low & Rare (1-2) \\
\hline Parosteal & Low & Rare (4) \\
\hline
\end{tabular}




\begin{tabular}{|c|c|c|c|c|c|}
\hline Trial Name & Disease cohort & Treatment & No patients & $\begin{array}{l}\text { Primary } \\
\text { Outcome } \\
\text { measure }\end{array}$ & Reference \\
\hline \multicolumn{6}{|c|}{ Newly diagnosed Disease } \\
\hline EuroEwing2012 & $\begin{array}{l}\text { SR: Localised } \\
\text { HR: pulmonary } \\
\text { metastases (R2) } \\
\text { Extra-pulmonary } \\
\text { metastases (R3) }\end{array}$ & $\begin{array}{l}\text { VIDE x } 6 \text { VAI /VAC x 8: +/-Sx +/-RT vs } \\
\text { VDC/IE +/-Sx +/-RT (Randomisation 1) } \\
\text { +/- Zol (Randomisation 2) }\end{array}$ & 600 & EFS & ISRCTN92192408 \\
\hline Ewing 2008 & $\begin{array}{l}\text { Localised SR (continued } \\
\text { from EE99) }\end{array}$ & $\begin{array}{l}\text { VIDE x } 6 \text { VAI/VAC } \times 8:+/-S x+/-R T \text { vs +/- } \\
\text { Zol }\end{array}$ & \multirow[t]{3}{*}{1163} & \multirow[t]{3}{*}{ EFS } & \multirow[t]{3}{*}{ NCT00987636 } \\
\hline Ewing 2008 & Lung only metastases & $\begin{array}{l}\text { VIDE x } 6 \text { VAC } \text { x 8: +/-Sx +/-RT vs } \\
\text { Bu/Melphalan }\end{array}$ & & & \\
\hline Ewing 2008 & Metastatic & $\begin{array}{l}\text { VIDE x } 6 \text { VAC } \times 8:+/-S x+/-R T \text { vs } \\
\text { Bu/Treosulphan }\end{array}$ & & & \\
\hline AEWS 1031 & Localised & $\mathrm{VDC} / \mathrm{IE}+/-\mathrm{C} / \mathrm{T}$ & 693 & EFS & NCT01231906 \\
\hline AEWS 1221 & Metastatic & VDC/IE +/- Ganitumab & 330 & EFS & NCT02306161 \\
\hline $\begin{array}{l}\text { Italy } \\
\text { ISG/AIEOP EW-1 }\end{array}$ & Localised & $\begin{array}{l}\text { Standard treatment (as per protocol ISG } \\
\text { SSG III) vs. dose-intensification } \\
\text { and shorter length of treatment }\end{array}$ & 220 & EFS & NCT02063022 \\
\hline \multicolumn{6}{|c|}{ Recurrent Disease } \\
\hline rEECur & Recurrent, refractory & C/T vs IT vs G/D vs High Dose Ifos & $\begin{array}{l}275 \text { for phase II } \\
390 \text { for phase III }\end{array}$ & ORR & ISRCTN36453794 \\
\hline
\end{tabular}

AIEOP, Associazione Italiana Ematologia Oncologia Pediatrica; Bu, busulphan; C/T, cyclophosphamide plus topotecan; COG, Children's Oncology Group; G/D, gemcitabine plus docetaxel; EFS, Event Free Survival; HR, high risk; IE, ifosfamide plus etoposide; ISG, Italian Sarcoma Group; IT, irinotcan plus temozolomide; ORR, Objective Response Rate, RT, radiotherapy; SR, Standard risk; Sx, surgery; VAC, vincristine, dactinomycin, cyclophosphamide; VAl, vincristine, dactinomycin, and ifosfamide; VC, vincristine plus cyclophosphamide; VDC, vincristine, doxorubicin, and cyclophosphamide; VIDE, vincristine, ifosfamide, doxorubicin, and etoposide; Zol, zolendronic acid. 
Table 3 PARP inhibitor combination studies

\begin{tabular}{|l|l|l|l|l|}
\hline $\begin{array}{l}\text { Study } \\
\text { Sponsor }\end{array}$ & $\begin{array}{l}\text { Indication, } \\
\text { age entry criteria } \\
\text { No. patients with ES entered }\end{array}$ & $\begin{array}{l}\text { PARP inhibitor, (schedule if } \\
\text { detailed) }\end{array}$ & $\begin{array}{l}\text { Cytotoxic Agent, } \\
\text { (schedule) }\end{array}$ & Reference \\
\hline COG & $\begin{array}{l}\text { Paediatric phase } 1 \\
>12 \text { months } \leq 21 \text { yrs }\end{array}$ & $\begin{array}{l}\text { Talazoparib } \\
\text { (D1-6) }\end{array}$ & $\begin{array}{l}\text { Temozolomide } \\
\text { (D2-6) }\end{array}$ & NCT02116777 \\
\hline MGH & ES Age $\geq 16$ years & $\begin{array}{l}\text { Olaparib } \\
\text { (D 1-7) }\end{array}$ & $\begin{array}{l}\text { Temozolomide } \\
\text { (D1-7) }\end{array}$ & NCT01858168 \\
\hline $\begin{array}{l}\text { SARC } \\
\text { Arm 1 }\end{array}$ & ES Age $\geq 13$ years & $\begin{array}{l}\text { Niraparib } \\
\text { (D1-7; D1-14; Continuous) }\end{array}$ & $\begin{array}{l}\text { Temozolomide } \\
\text { (D2-6) }\end{array}$ & NCT02044120 \\
\hline $\begin{array}{l}\text { SARC } \\
\text { Arm2 }\end{array}$ & ES Age $\geq 13$ years & $\begin{array}{l}\text { Niraparib } \\
\text { (D1-7) }\end{array}$ & $\begin{array}{l}\text { Irinotecan } \\
\text { (D2-6) }\end{array}$ & NCT02044120 \\
\hline $\begin{array}{l}\text { St Jude } \\
\text { Children's } \\
\text { Research } \\
\text { Hospital }\end{array}$ & $\begin{array}{l}\text { Paediatric phase } 1 \\
\text { Age: }>12 \text { months } \leq 25 \text { years }\end{array}$ & $\begin{array}{l}\text { Talazaparib } \\
\text { (D1-6) }\end{array}$ & $\begin{array}{l}\text { Irinotecan } \\
\text { (D2-6) }\end{array}$ & NCT02392793 \\
\hline $\begin{array}{l}\text { ITCC } \\
\text { Cohort D: Age: }>12 \text { months } \leq 18 \text { years }\end{array}$ & Olaparib & Irinotecan & NCT02813135 \\
\hline
\end{tabular}

COG- Children's Oncology Group; MGH - Massachusetts General Hospital; SARC-Sarcoma Alliance for Research through Collaboration; ITCC; ESMART, European Proof-of-Concept Therapeutic Stratification Trial of Molecular Anomalies in Relapsed or Refractory Tumors 
Table 4 Subtypes of Chondrosarcoma and indications for systemic chemotherapy

\begin{tabular}{|c|c|c|c|}
\hline WHO classification & Grade & Incidence, \% & $\begin{array}{l}\text { Indication for systemic } \\
\text { chemotherapy }\end{array}$ \\
\hline Conventional central & $\begin{array}{l}\text { I / atypical cartilaginous } \\
\text { tumour, II, III }\end{array}$ & Common $>75$ & No defined role \\
\hline Conventional peripheral & $\begin{array}{l}\text { I / atypical cartilaginous } \\
\text { tumour, II, III }\end{array}$ & 10 & No defined role \\
\hline Periosteal & Low & $<1$ & No defined role \\
\hline Dedifferentiated & High & 10 & $\begin{array}{l}\text { Consider adjuvant chemotherapy in } \\
\text { younger patients with localised } \\
\text { disease and for palliation in good PS }\end{array}$ \\
\hline Mesenchymal & high & $<2$ & $\begin{array}{l}\text { Recommended as adjuvant } \\
\text { chemotherapy and for palliation }\end{array}$ \\
\hline Clear cell & Low & $<2$ & No defined role \\
\hline
\end{tabular}

PS, performance status 
